\title{
Info-Communication Systems Based on E-mail and SMS Technologies
}

\author{
Andranik E. Mkhitaryan \\ Institute for Informatics and Automation Problems of NAS RA \\ e-mail: and.mkhitaryan@gmail.com
}

\begin{abstract}
The features of the widespread systems for the exchange of messages in computer and cellular networks, the prerequisites for the creation of combined messaging systems using IP and GSM technologies are considered. The peculiarities of the construction of hybrid e-mail / SMS info-communication systems are considered.
\end{abstract}

Keywords: mail2sms, e-mail, SMS, notification.

\section{Introduction}

Electronic mail is a system to send/receive text messages between computers by the Internet. Despite the fast delivery of the letter to the addressee, e-mail is a typical "on demand" system. The reading of the delivered message by the addressee depends on the time when he/she requests it from the e-mail provider. Another worldwide system for text message exchange is SMS. Unlike e-mail, SMS is not a postal system: the size of the transmitted message is limited, message delivery is possible only in the coverage area of the cellular network or according to the roaming agreements of the local cellular operator. The undeniable advantage of SMS technology is the delivery of the message directly into "the pocket" of a mobile subscriber. The limitations typical of e-mail and SMS can be overcome by the use of integrated, "in one bottle," mutually complementary network and SMS technologies. At the same time, the problem of "long-range" of a particular SMS-service is solved using the Internet as a transport for SMS messages (Websms).

\section{Solution}

The problem of "on demand" can be solved by the use of e-mail related SMS-systems to promptly notify the recipient of incoming e-mails in his mailbox [1], [2]. These technologies 
usually use special program selectors, built into the mail server that allocate messages for which a notification is required to be sent to the recipient (according to the permissive list with the corresponding e-mail addresses on the server) and provides necessary data to form an SMS notification for the particular SMS server, which has a gateway to the cellular network of the region. SMS server in the Internet environment is equipped with a GSM modem - a gateway to a given cellular network, which provides the formation and transmission of SMS notifications. In the considered case, the initiative of selecting from among the incoming messages those for which it is desirable to receive an SMS notification, is assigned to the recipient.

Another approach is possible when creating a notification system: in this case, an application for sending an SMS notification to the addressee is sent directly by the sender when preparing the letter [3]. In such cases, the message should contain certain signs indicating the need to send the letter to the addressee together with SMS notification. Bearing in mind that email notification systems are based on the use of SMS technologies, it is natural to combine the info-communication resources of e-mail and SMS technologies in the form of one service for the user of an e-mail. In such systems, the ability of e-mail account users to send SMS notifications to the specified cellular networks is not the only possible way, because in these systems it is easy to integrate "in one package" for an e-mail user: a wide range of services related to the use of SMS technologies (transmission of SMS notifications via e-mail, group mailings of SMS, etc.). Using such a hybrid "E-mail + SMS" technology allows creating a unified system for the user of Webmail to access all the info-communication resources used in this mail system, both e-mail and SMS.

\section{Multiple Approaches}

There are two possible approaches to creating such hybrid systems:

a) Systems with the selection of incoming mail from the mail server according to certain characteristics and transfer of the necessary data to SMS server for configuration and sending SMS (Figure 1). The criterion for selecting an incoming message containing a request for operations with SMS can be marked by the sender in the

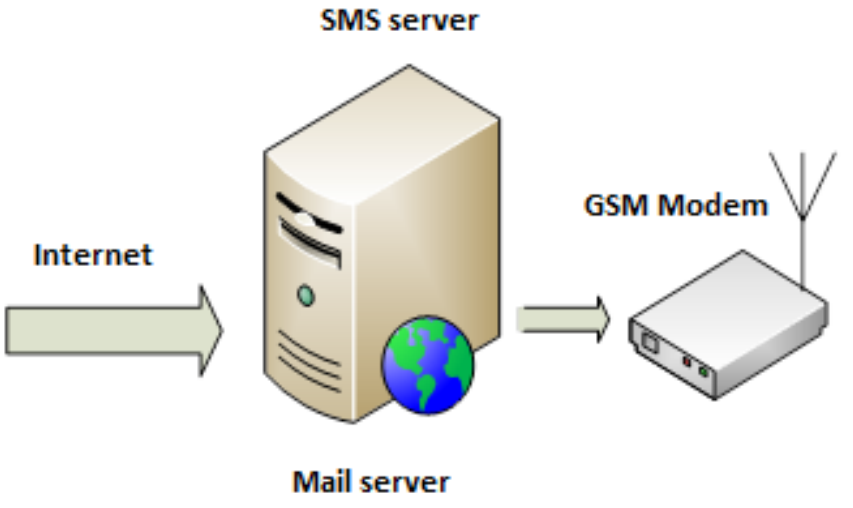

Fig. 1. Structure of the first approach. "subject" section. Accordingly, when composing a letter in the subject section, a command line is formed containing a request for the GSM controller to perform a specified specific operation. The selector of mail server selects e-mails containing a command in the subject section from the incoming e-mail stream. From the letter, in turn, the attributes of the letter are highlighted and together with the content of the subject are transferred from the mail server to the GSM controller for further processing in accordance with the command contained in the command line. 
b) Systems that operate with copies of letters with the necessary target designations sent directly to the SMS server to create and send an SMS to the recipient (Figure 2).

In this case, the system is presented in the form of an independent e-mail / SMS infocommunication resource, not directly connected to Webmail services that uses the e-mail as a

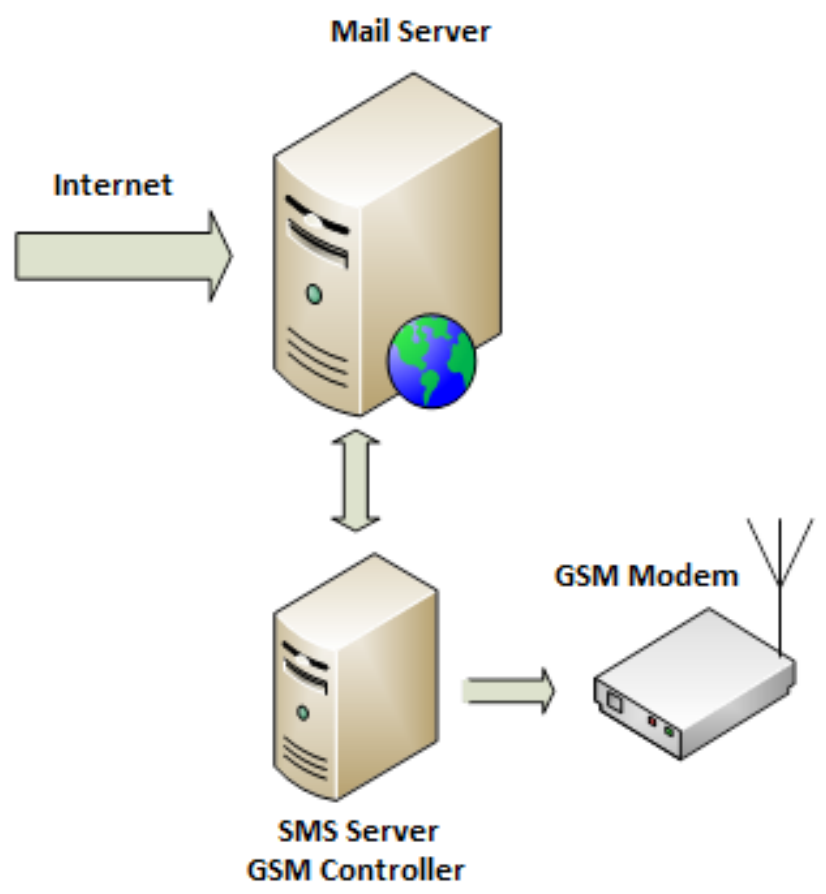

Fig. 2. Structure of the second approach. transport of access to the resource for the user. User access to the system is done directly from the Webmail page of the user, without requiring additional access to other resources. During the preparation of the letter, the user needs to send a copy of the letter to the mail address of the system (to request a notification) or send an email directly to the system. Such a solution does not require a binding to a specific e-mail provider. These provisions are used in the UNIMail-ASNET project [4]. The server acts as an ordinary e-mail user. For the convenience of Webmail users, the mechanisms for accessing and managing SMS options are combined with e-mail preparation operations with a minimum number of request commands to the UNIMail server. All operations with the system are made directly from the Webmail user's page when composing the letter. In the highlighted markers of the "subject" field, the command of the message contains the information (phone numbers of the addressees, management of the "black list") for the UNIMail server to perform the corresponding operations. A copy of the letter should be sent to the e-mail address of the server for further processing. The choice of the mode requested by the user (notification or sending of sms) is made automatically by the system, analyzing the address part of the message copy being processed.

Commands with descriptions:

$>$ *notice to...(phone numbers)* - Parallel to the letter send SMS notification to the addressee/addressees

$>*^{*}$ sms to... (phone numbers)* - Send an SMS to the addressee/addressees

$>$ *add to black list* - Include in the "black list" of the blocked recipient

$>$ *del from black list* - Exclude the blocked addressee from the "black list" 


\title{
4. Conclusion
}

Besides many undisputable advantages, e-mail is a typical "on demand" info-communication resource. However, another technology - SMS, does not have such a problem and allows you to send text messages directly to the addressee's mobile phone. The use of e-mail/SMS hybrid system will help users overcome that disadvantage of e-mail.

In the article two different approaches of such systems are presented. Both advantages and disadvantages of both models are discussed. The possible design for them and the use cases are described.

\section{References}

[1] Д. Геворкян, А. Нанасян и К. Хачатрян, «Новые WEB ресурсы ASNET.AM», Proceedings of International Conference of Computer Science and Information Technologies, CSIT-2011, Ереван, pp. 311-312, 2011.

[2] D. Gevorkyan, K. Khachatryan, A. Nanassian, A. Petrosyan, G.Petrosyan, V. Sahakyan and E. Vardanyan, "Mail informer- selective incoming instant phone notification system”, Proceedings of International Conference Computer Science and Information Technologies, CSIT, Yerevan, Armenia, pp. 466-467, 2009.

[3] А. Нанасян и К. Хачатрян «Mail2sms.asnet.am - система оповещения о входящих письмах», Proceedings of International Conference of Computer Science and Information Technologies CSIT-2013. Ереван, 2013.

[4] А. Мхитарян, Э. Матвеев, А. Нанасян, В. Саакян и А. Petrosyan, “Гибридная инфокоммуникационная email/sms система UNIMail”, Proceedings of International Conference of Computer Science and Information Technologies, CSIT, Yerevan, Armenia, pp. 389-391, 2017.

Submitted 22.11.2017, accepted 12.02.2018.

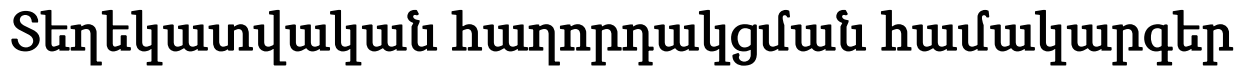

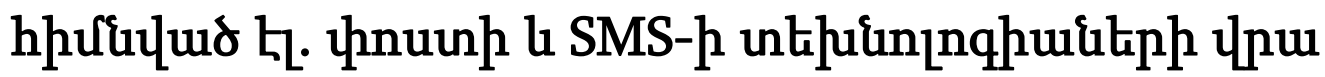

\author{
U. Uhuppunjuid \\ Uựฺnนุnนu
}

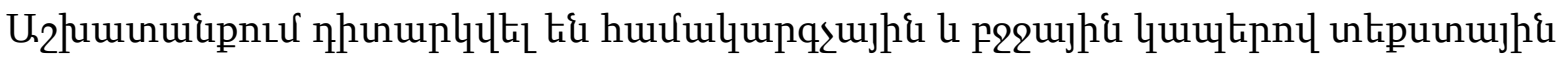

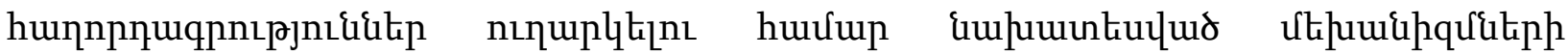

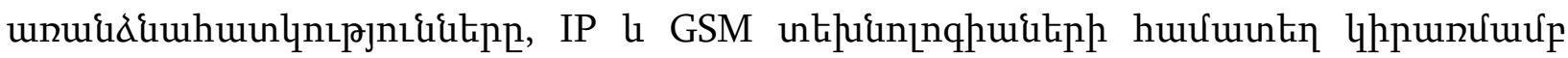

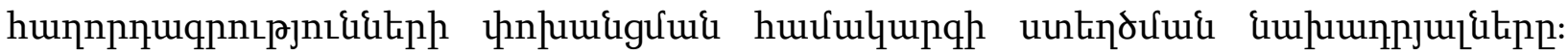




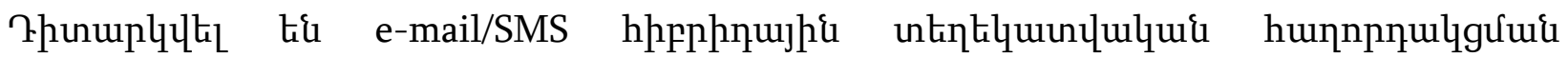

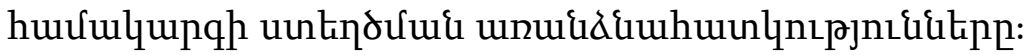

\title{
Инфо-коммуникационные системы на базе технологий e-mail и sms
}

\begin{abstract}
А. Мхитарян
Аннотация

Рассмотрены особенности распространенных систем обмена письменными сообщениями в компьютерных и сотовых сетях, предпосылки создания совмещенных систем передачи сообщений, использующих технологии IP и GSM сетей. Рассмотрены особенности построения гибридных e-mail/sms инфокоммуникационных систем.
\end{abstract}

